\title{
VIEWPOINT
}

\section{Strategies to Improve Mentorship and Foster Career Advancement in Academic Hospital Medicine}

\author{
Doris Lin, MD, MS@ and R. Michelle Schmidt, MD, MPH \\ J Gen Intern Med 37(10):2556-8 \\ DOI: $10.1007 / \mathrm{s} 11606-021-07371-7$ \\ (c) The Author(s) under exclusive licence to Society of General Internal \\ Medicine 2022
}

Department of Medicine, Baylor College of Medicine, 1504 Taub Loop, 2PA 71009, Houston, TX, USA.
$\mathrm{C}$ areer advancement and promotion of academic hospitalists has lagged behind despite the existence of hospital medicine for over two decades. As it remains a popular career choice for graduating internal medicine residents, the field has seen a rapid rise in junior faculty. However, there continues to be a limited number of those who have advanced to the senior faculty level, namely associate or full professor. ${ }^{1}$ One reason for this current gap is the lack of mentorship for hospitalists. In 2011, Harrison et al. ${ }^{2}$ found an acute need for mentoring and career development programs, and Reid et al. ${ }^{3}$ found that lack of mentorship was a key factor with failure to produce scholarly activity. These articles, published ten years ago, identified the tremendous need for academic hospitalist mentorship. Since then, little has been published regarding implementation of successful programs. In this article, we reflect on the growth of the field, describe how traditional mentorship models pose a challenge, and provide strategies dedicated to meet the needs of a hospitalist.

The hospitalist movement began in the mid-1990s and grew out of a need to incorporate internists who could focus specifically on the care of hospitalized patients. As Medicare began to reduce reimbursement, decreasing length of stay and cost conscious care became paramount initiatives for hospital administrators. ${ }^{4}$ Hiring hospitalists whose motives were more aligned with hospital objectives evolved to fill that need. ${ }^{4}$ Furthermore, in the early 2000s, the Accreditation Council for Graduate Medical Education created resident duty hour restrictions and caps which also spurred the need for more inpatient coverage. ${ }^{5}$ The demand for increased trainee oversight, staffing non-teaching services, and co-management with surgical services generated further growth.

Over the past two decades, hospitalists have become leaders in quality improvement, patient safety, high value care, and

Prior Presentations None.

Received October 17, 2021

Accepted December 16, 2021

Published online January 11, 2022 hospital metrics. However, the number of those promoted in academic rank remains low. In a cross-sectional analysis of more than 1500 academic hospitalists at the top 25 US internal medicine residencies, $88.3 \%$ were instructors or assistant professors, while only $9 \%$ were associate and $2.7 \%$ full professors. ${ }^{1}$ The Association of American Medical Colleges 2020 data demonstrated about $20 \%$ of Internal Medicine faculty in US medical schools reached full professor which displays the stark contrast in promotion specific to hospitalists. ${ }^{6}$ Previously recognized barriers to promotion include lack of leadership support, limited protected scholarly time, heavy clinical commitment, inadequate mentorship, and lack of additional training in research-related skills such as project development and sophisticated data analysis. ${ }^{2,3,7}$

More specifically, mentorship has been shown to play a key role in career advancement with studies linking it to improved faculty retention, success in research productivity, reduction in time to promotion, and increased work satisfaction. ${ }^{8,9} \mathrm{Al}-$ though there is an abundance of literature on mentoring models and strategies for academic faculty in general, many of the concepts are not feasible for hospitalists. The traditional dyadic model poses a challenge because there remains a dearth of senior faculty to serve as mentors. Multiple or group mentoring could serve as a possible alternative. However, in this model, the individual carries the burden of developing their own network. A number of academic hospitals have turned to peer mentoring as a reasonable solution. ${ }^{10-12}$ This model groups members of similar rank and interest to serve as both mentor and mentee to each other. With limited senior faculty and the majority of academic hospitalists currently employed at the assistant professor or instructor rank, facilitated peer mentoring appears to be a logical alternative. ${ }^{10}$

\section{OPTIMIZING MENTORSHIP FOR THE ACADEMIC HOSPITALIST}

\section{Strategies for Academic Leaders}

(1) Set clear expectations

Clear understanding of prerequisites for promotion has been positively associated with production of more peerreviewed publications which are typically necessary for advancement in academic settings. ${ }^{3}$ Additionally, some institutions have developed clinical pathways which may be more aligned to the goals of a hospitalist who spends 
more time in the clinical setting. It is imperative to educate junior faculty early by clearly outlining the promotion criteria on an aligned pathway, offering available resources to build a curriculum vitae/portfolio, and defining publication requirements.

(2) Provide protected time for academic pursuits

It has been shown that academic hospitalists with protected time tend to be more productive. ${ }^{3,7,13}$ One institution, recognizing the importance of maintaining a stable group of mature hospitalists, supported protected time for scholarly activities irrespective of external funding for those committed to career advancement. ${ }^{13}$ In addition to protected time for the mentee, protected time and recognition should be considered for senior mentors/facilitators as their guidance and experience is crucial.

(3) Introduce activities and types of publications that may be more conducive to the busy clinician

Many hospitalists lack advanced training in project development and data analysis. It would be worthwhile to introduce other avenues of publication such as case reports, perspectives, narrative reviews, editorials, and clinical images all of which are offered in many medical journals. Additionally, education on how activities including learner teaching, committee membership, and administrative roles may be incorporated into a professional portfolio is vital.

(4) Create facilitated peer mentoring groups

Facilitated peer mentoring groups members who have similar rank and interests to work collaboratively towards career advancement. The group is guided by a senior facilitator of higher academic rank whose main goals are to be accessible and supportive. Currently, there appears to be one article that describes the implementation of a facilitated peer mentoring program specific to hospitalists. ${ }^{10}$ The program helped members identify their own career goals and aided others in expanding their collaborative network. However, this was a small single-center study that did not focus on other important domains such as resources and methods for career advancement. We suggest implementation of such a program that also includes these domains.

\section{Strategies for Individual Hospitalists}

(1) Seek leadership support

Academic medical centers have eagerly hired hospitalists to mitigate busy inpatient services while providing efficiency and availability in quality and education. However, many academic leaders have not evolved in recognizing hospitalists as strong contributors in academia. In order to "earn" leadership support and protected time, individual hospitalists should consider establishing a
Table 1 Optimizing Mentorship in Academic Hospital Medicine

Strategies for academic leaders

1. Set clear expectations by assisting junior faculty in:

- Identifying career goals

- Building their curriculum vitae

- Determining an aligned pathway to promotion

- Developing scholarly activities

- Building an educational and/or clinical portfolio

2. Provide protected time for academic pursuits

3. Introduce activities and publications more conducive to hospitalists

4. Create a facilitated peer mentoring program by:

- Grouping junior faculty with similar interests

- Identifying senior faculty to serve as group facilitators/mentors

Strategies for individual hospitalists

1. Seek leadership support and protected time by:

- Finding your niche

- Developing projects

- Participating in administrative and educational activities

2. Participate in internal and external faculty development programs and/ or fellowships

3. Become a member in local, regional, and national organizations such as SGIM and SHM

niche, demonstrate work on scholarly projects, and show a commitment to their own career development.

(2) Consider further training through faculty development and/or hospitalist fellowships focused on academic scholarship

Increased participation in faculty development and/or fellowships geared towards scholarship could aid in filling the current skills gap in educational and research methods. This could also provide long-term benefit as these trained hospitalists could then mentor their peers on these advanced skills. ${ }^{13,14}$

(3) Participate in local, regional, and national organizations Membership and attendance at meetings organized by the Society of General Internal Medicine (SGIM) and Society of Hospital Medicine (SHM) may be highly beneficial to a hospitalist's career trajectory. Participation in these meetings may offer an excellent opportunity for networking, establishing external mentoring relationships, and both offer academic academies.

Twenty-five years after the emergence of the hospitalist movement, we are still lacking mentorship for the academic hospitalist. By combining key domains recognized in the literature as imperative to hospitalist success into a mentorship program, we suggest the strategies detailed above and summarized in Table 1 in which mentorship can be improved within academic hospitalist programs. Lack of mentorship should no longer be a barrier to achieving a more even distribution of academic rank amongst hospitalists.

Corresponding Author: Doris Lin, MD, MS; Department of Medicine, Baylor College of Medicine, 1504 Taub Loop, 2PA 71009, Houston, TX 77030, USA (e-mail: Doris.Lin@bcm.edu).

\section{Declarations:}

Conflict of Interest: The authors declare that they do not have a conflict of interest. 


\section{REFERENCES}

1. Sumarsono A, Keshvani N, Saleh SN, et al. Scholarly productivity and rank in academic hospital medicine. $J$ Hosp Med. 202 1; 16(9):545-548.

2. Harrison R, Hunter AJ, Sharpe B, Auerbach AD. Survey of US academic hospitalist leaders about mentorship and academic activities in hospitalist groups. J Hosp Med. 2011;6(1):5-9.

3. Reid MB, Misky GJ, Harrison RA, et al. Mentorship, productivity, and promotion among academic hospitalists. J Gen Intern Med. 2011;27(1):23-7.

4. Wachter RM, Goldman L. Zero to 50,000 - The $20^{\text {th }}$ anniversary of the hospitalist. N Engl J Med. 2016;375(11):1009-1011.

5. Harrison R, Allen E. Teaching internal medicine residents in the new era. Inpatient attending with duty-hour regulations. J Gen Intern Med. 2006 May;21(5):447-52.

6. Association of American Medical Colleges. Faculty Roster: US Medical School Faculty 2020 Report. Available at: https://www.aamc.org/datareports/faculty-institutions/interactive-data/2020-us-medical-schoolfaculty. Accessed September 1, 2021.

7. Cumbler E, Rendon P, Yirdaw E, et al. Keys to career success: resources and barriers identified by early career academic hospitalists. J Gen Intern Med. 2018;33(5):588-589.

8. Wingard DL, Garman KA, Reznik V. Facilitating faculty success: outcomes and cost benefit of the UCSD National Center of Leadership in Academic Medicine. Acad Med. 2004;79(10 suppl):S9-11.
9. Morrison LJ, Lorens E, Bandiera G, et al. Impact of a formal mentoring program on academic promotion of Department of Medicine faculty: A comparative study. Med Teach. 2014;36(7):608-614.

10. Choi JJ, Evans AT, McNairy ML. Facilitated peer mentoring: filling a critical gap in academic hospital medicine. J Hosp Med. 2021;15(9):563565.

11. Rosenthal MA, Sharpe BA, Haber LA. Using peer feedback to promote clinical excellence in hospital medicine. J Gen Intern Med. 2020 Dec;35(12):3644-3649.

12. Nemeth A, Chisty A, Spagnoletti CL, Stankiewicz CA, Burant C, Ramani S. Exploring mentoring experiences, perceptions, and needs of general internal medicine clinician educators navigating academia: a mixed-methods study. J Gen Intern Med. 2021 May;36(5):1229-1236.

13. Howell E, Kravet S, Kisuule F, Wright SM. An innovative approach to supporting hospitalist physicians towards academic success. J Hosp Med. 2008;3(4):314-318.

14. Sehgal NL, Sharpe BA, Auerbach AA, Wachter RM. Investing in the future: building an academic hospitalist faculty development program. $J$ Hosp Med. 2011 Mar;6(3):161-6.

Publisher's Note Springer Nature remains neutral with regard to jurisdictional claims in published maps and institutional affiliations. 